\title{
A mechanism for bentonite buffer erosion in a fracture with a naturally varying aperture
}

\author{
Christopher Reid*, Rebecca Lunn, Gráinne El Mountassir and Alessandro Tarantino \\ Department of Civil and Environmental Engineering, University of Strathclyde, Glasgow G1 1XQ, UK
}

[Received 10 October 2014; Accepted 22 April 2015; Associate Editor: Katherine Morris]

\section{ABSTRACT}

In the deep geological disposal of nuclear waste in crystalline rock, erosion of the bentonite buffer may occur during periods of glaciation. Previous researchers have examined the mechanism and rates of extrusion and erosion for purified montmorillonite samples in smooth planar fractures. In this paper, we investigate the influence of using MX-80 material (as delivered, i.e. including accessory minerals) and a naturally varying aperture on bentonite erosion. A bespoke fracture flow cell was constructed for this purpose and flow through conducted with deionized water. Throughout the experiment, gravimetric analysis was undertaken on the effluent and the swelling pressure of the bentonite monitored. Quantitative image analysis of the extrusion process was also undertaken. When the swelling pressure data were analysed, alongside both the oscillations in erosion rate and the area of the accessory-mineral ring, a two-stage mechanism governing the erosion process became apparent. Once an accessory-mineral ring had formed at the edge of the extruded material, further increases in swelling pressure resulted in a breach in the accessorymineral ring, triggering an erosive period during which, the mineral ring was supplemented with additional minerals. The cycle repeated until the ring was sufficiently strong that it remained intact. This observed process results in erosion rates one order of magnitude less than those currently used in long-term safetycase calculations.

Kerwords: bentonite, montmorillonite, buffer, erosion, nuclear-waste disposal.

\section{Introduction}

THIS study focuses on the KBS-3V concept for the deep geological disposal of high level nuclear waste in crystalline rock, the current reference disposal concept of SKB and Posiva. The bentonite buffer plays an integral role in the multi-barrier system for the isolation of high level nuclear waste and is required to perform a number of functions. The buffer must generate a swelling pressure of between 2 and $10 \mathrm{MPa}$ to suppress any detrimental

* E-mail: christopher.reid@strath.ac.uk DOI: 10.1180/minmag.2015.079.6.23 microbial activity. It must restrict all transport processes across the buffer to being diffusive and must remain plastic enough to buffer the waste canister against any small tectonic movements (Juvankoski et al., 2012). The buffer consists of a series of discs and rings of MX- 80 bentonite (SKB and Posiva's reference buffer material, consisting of 75-90\% montmorillonite) placed concentrically over and around the waste canister. Compacted bentonite pellets are used to fill the annular gap between the host rock and the rings with the buffer having a target bulk density of $1950-2050 \mathrm{~kg} / \mathrm{m}^{3}$, once fully saturated (SKB 2011, Vol I). Saturation occurs due to the uptake of groundwater from the surrounding host rock, via any transmissive rock
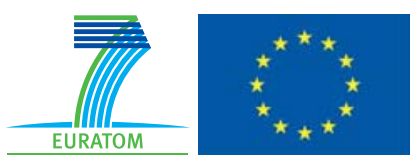

The publication of this research has been funded by the European Union's European Atomic Energy Community's (Euratom) Seventh Framework programme FP7 (2007-2013) under grant agreements $n^{\circ} 249396$, SecIGD, and n`323260, SecIGD2. 


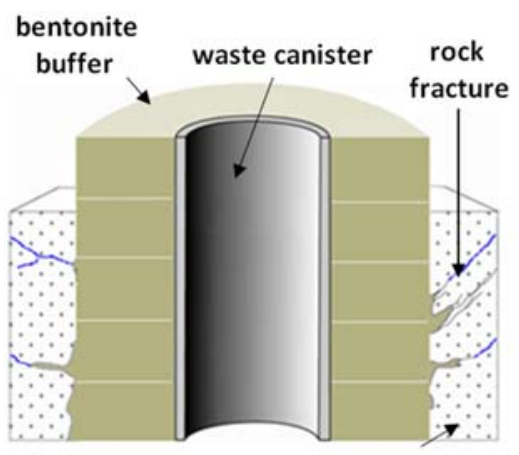

a)

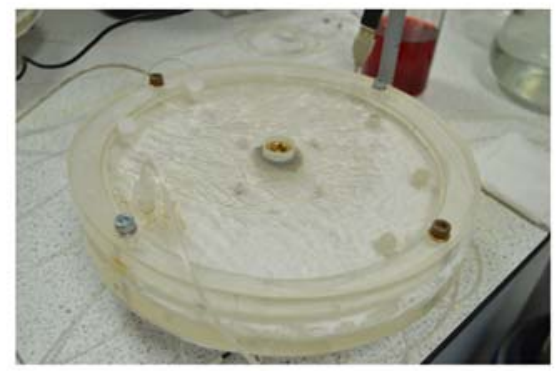

b)

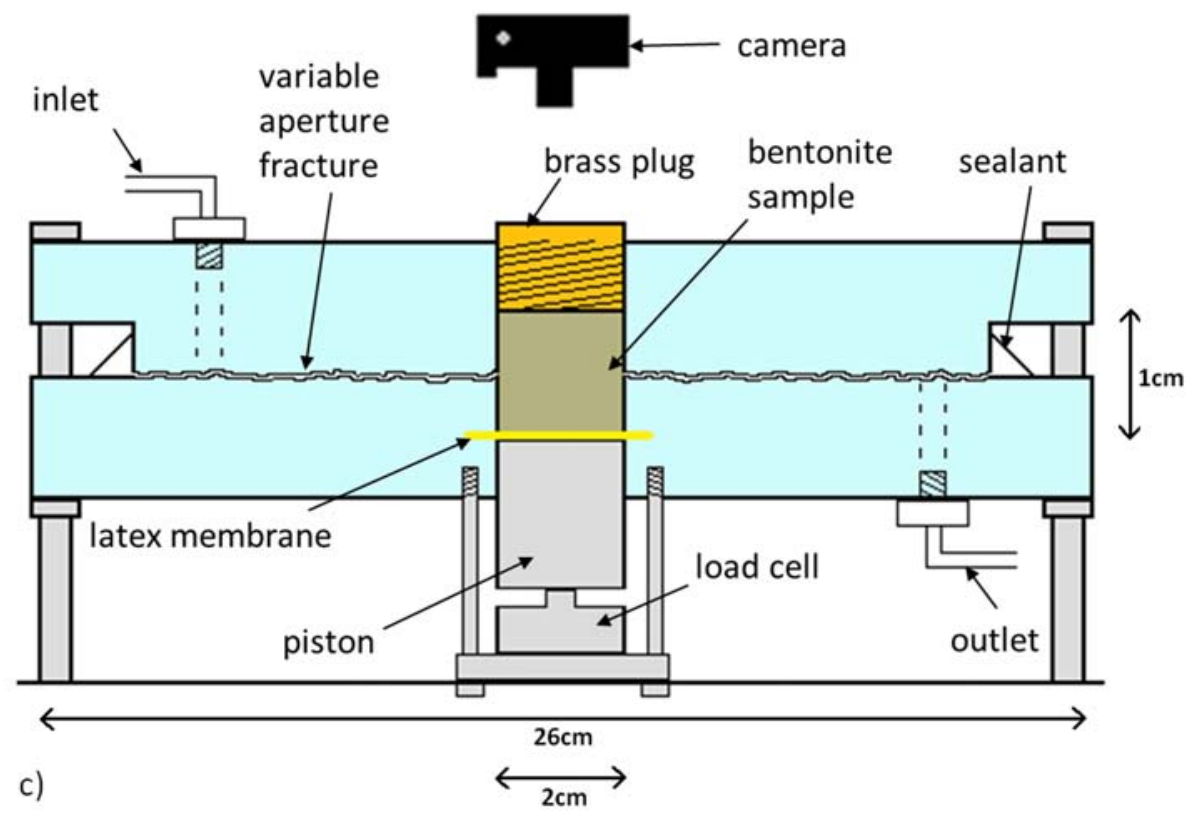

FIG. 1. (a) Cross-section of deposition hole; (b) image of experimental apparatus; (c) schematic cross-section of flow cell.

fractures intersecting the deposition hole as illustrated in Fig. 1a. The buffer material subsequently swells within the confines of the deposition hole. The buffer is not fully confined in the deposition hole, however, as it may continue to swell into any transmissive cross-cutting rock fractures.

The ability of the buffer to meet its performance criteria is dependent on the prevailing hydrogeochemical conditions, which will be transient throughout the hundreds of thousands of years required for the repository to maintain its integrity. As long as the groundwater remains sufficiently saline, the cations present between interlayer montmorillonite sheets, which act to maintain electrical neutrality, will be in equilibrium with those present in the groundwater. If the concentration of cations in the groundwater should fall below a critical threshold, however, due to the intrusion of dilute groundwater, cations will diffuse from the buffer to the groundwater due to the concentration gradient, allowing negative, repulsive forces to dominate between montmorillonite sheets. The buffer will therefore form a low shear-strength colloidal sol at the buffer/groundwater interface, which will be susceptible to erosion by the flowing 
groundwater. Intrusion of dilute groundwater to repository depth is possible during periods of glaciation, which may last many millennia and recur up to eight times during the typical repository assessment period of 1,000,000 y (SKB 2011, Vol II). There are two potential consequences of buffer erosion. (1) Mass loss due to erosion may result in the dry density of the buffer falling below its target value, negating many of its functions. (2) In the event of a breached canister and radionuclide diffusion across the buffer, erosion may facilitate radionuclide transport back to the biosphere via sorption onto montmorillonite colloids.

Considerable research has been carried out in order to better understand the phenomenon of buffer erosion under repository-relevant conditions. Vilks and Miller (2010) examined the erosion rate of bentonites of various compositions with respect to $\mathrm{Na} / \mathrm{Ca}$ content in a smooth-walled artificial fracture cell and a natural granite fracture. In particular, the effects of solution chemistry, velocity, fracture aperture and inclination were examined. The study found colloid generation and bentonite erosion were significantly higher with deionized water than with solutions containing millimolar concentrations of dissolved salts.

Schatz et al. (2013) examined the extrusion behaviour and erosion rates of purified montmorillonites of various compositions with respect to $\mathrm{Na} / \mathrm{Ca}$ content in an artificial, smooth-walled fracture system. This work was undertaken with a variety of solution chemistries and velocities and found purified $\mathrm{Na}$ and $50 / 50 \mathrm{Ca} / \mathrm{Na}$ montmorillonite to be erosive at solution chemistries of $\leq 0.25 \mathrm{~g} / 1 \mathrm{NaCl}$. Erosion rates also correlated well with flow velocities under the most dilute conditions of solution chemistry.

In recent work supporting an application for a licence to construct a repository for spent fuel at Forsmark, Sweden, SKB included a model to quantify buffer erosion in a fracture intersecting a deposition hole carrying groundwater of low ionic strength. The model, developed by Neretnieks et al. (2009), is based on the buffer consisting solely of $100 \%$ pure $\mathrm{Na}$ montmorillonite and hence gives highly conservative estimates of montmorillonite release rates (SKB, 2011, Vol II):

$$
R_{\text {erosion }}=\mathrm{A} \delta v^{0.41}
$$

where $R_{\text {erosion }}$ is the montmorillonite release rate $(\mathrm{kg} / \mathrm{y}), \mathrm{A}$ is a constant (27.2), $\delta$ is the fracture aperture $(\mathrm{m})$ and $v$ is fluid velocity $(\mathrm{m} / \mathrm{y})$. SKB (2011) also stated that the loss of montmorillonite may be significantly reduced by filtering effects, possibly even preventing colloid release entirely. Neretnieks et al. (2009) proposed this theory after observing that, during expansion of bentonite in a glass slit, a region of enriched accessory minerals forms where the gel density is too low to facilitate further transport of the accessory minerals. The montmorillonite gel moves independently, leaving the accessory minerals behind. Richards and Neretnieks (2010) and Richards (2010) continued this research by exploring the effectiveness of precompacted filter beds of bentonite accessory minerals of various compositions and grain sizes in the filtration of montmorillonite colloids in filter columns.

An independent study commissioned by the Swedish Radiation safety authority (SSM) (Apted et al., 2010), into the potential consequences of buffer erosion, has also addressed the issue of erosion mitigation by filter-bed formation. They found there was a lack of empirical data to suggest that filter cakes actually form upon the extrusion and erosion of bentonite into a fracture. Further, they noted that if filter cakes did form, there was insufficient evidence to determine their effectiveness in straining montmorillonite colloids. Apted et al. (2010) also questioned the durability and stability of such a filter in the long term.

The vast majority of research into buffer erosion in fractures has been carried out using purified montmorillonite samples, devoid of any accessory minerals. Yet accessory minerals, such as quartz, plagioclase and potassium feldspar, may account for $10-25 \%$ of the buffer (Kiviranta and Kumpulainen, 2011). Previous research has also focused on smooth-walled fracture cells. Yet the variability of a natural fracture aperture may aid the process of accessory-mineral filter formation as larger accessory minerals will be strained as the material extrudes into the intersecting fracture.

This study investigated the mechanisms governing bentonite erosion in a fracture with a naturally varying aperture. MX- 80 bentonite was used, as it is proposed for geological disposal in the SKB and Posiva disposal concept. The aim of the study was to evaluate the level of conservatism in current models, such as that used in the KBS-3V safety case, by quantifying the effect of accessory minerals in reducing buffer erosion in natural fractures.

\section{Material and methods}

Figure $1 b$ shows the flow cell, which has a diameter of $26 \mathrm{~cm}$ and was constructed by taking a cast of a 
natural fracture present in a core of microgranite from Ailsa Craig, Scotland, using a clear, rigid, two-part epoxy resin (ABL Stevens resin supplies). The fracture face was cast at $2 \mathrm{~cm}$ thick and, once cured, was removed from the granite core. This process was then repeated on the original cast resulting in two epoxy resin plates, each $2 \mathrm{~cm}$ thick with complementary fracture faces which, when joined together, formed a perfect union. From the resulting fracture faces, a flow cell was manufactured. This was achieved by a very small rotation $\left(<1^{\circ}\right)$ of the top plate, such that the directionality of features specific to the fracture were retained while creating a small hydraulic aperture. The process was conducted under water to ensure that the presence of air bubbles in the fracture was avoided. The cell was then sealed around its circumference using a silicone sealant capable of curing under water. Water was then passed through the cell at a constant flow rate and the head difference across the cell recorded by way of stand pipes off the inlet and outlet. The hydraulic aperture was then determined for the cell using the cubic law (Witherspoon et al., 1979):

$$
Q=\frac{W \rho g b^{3} \Delta h}{12 \mu L}
$$

where $Q$ is the flow rate $\left(\mathrm{m}^{3} / \mathrm{s}\right), W$ is the width of the flow zone, $\rho$ is the density of water, $g$ is the acceleration due to gravity, $b$ is the hydraulic aperture (m), $\Delta h$ is the head difference, $\mu$ is the viscosity of water and $L$ is the length of the flow zone. Once the hydraulic aperture had been determined, bolt holes were drilled around the periphery of the plate to hold the cell together and lock it in place at this aperture. The average hydraulic aperture described in the experiment was $54 \mu \mathrm{m}$. The extent of flow in the flow cell was imaged using a dye injection and the elliptical flow area was then converted into an equivalent rectangular area of width, $W$ and length, $L$ to determine the equivalent hydraulic aperture. The original granite rock fracture was scanned using a scan control, micro-epsilon 2700-100 laser scanner and the data processed using imageJ software to reveal a standard deviation of $169 \mu \mathrm{m}$ in the roughness of a single fracture surface.

The compacted bentonite plug was housed in the fracture in the central compartment $(20 \mathrm{~mm}$ in diameter) recessed in the centre of the plate, which passed entirely through the top plate and protruded $5 \mathrm{~mm}$ into the bottom plate such that the fracture intersected the bentonite plug at its mid-point as detailed in Fig. 1c. The hole in the top plate was threaded to accommodate a screw to keep the bentonite plug in place. Provision was made for the mounting of a load cell (Omega LCM-302 2kN) on the underside of the bottom plate, directly below the bentonite plug and in contact with the bentonite plug through a latex membrane via a piston (see Fig. 1c). The load-cell measurements were used to calculate the swelling pressure of the bentonite in the central compartment.

The MX-80 sample was compacted uniaxially, using a Wykham Farrance $50 \mathrm{kN}$ loading frame and specially constructed compaction mould and loading ram, in accordance with Posiva's reference installed buffer conditions at a dry density of $1660 \mathrm{~kg} / \mathrm{m}^{3}$ and water content of $18 \%$ (Juvankoski et al., 2012). The water content was determined by oven drying a replica pellet (compacted under the same conditions and from the same sample) at $105^{\circ} \mathrm{C}$ for $24 \mathrm{~h}$. The pellet installed in the fracture had a diameter of $18.65 \mathrm{~mm}$ and a height of $10.3 \mathrm{~mm}$. Upon installation of the pellet into the flow cell, deionized water was injected at a constant flow rate of $1 \mathrm{ml} / \mathrm{min}$ using a peristaltic pump. This flow rate corresponded to a fluid velocity of $0.5 \mathrm{~mm} / \mathrm{s}$ in the fracture, determined from a dye-injection test using image analysis. Deionized water was used as a proxy for dilute glacial melt water, in order to induce the most erosive conditions. Gravimetric analysis was undertaken by filtration of the effluent every $24 \mathrm{~h}$ through a $0.2 \mu \mathrm{m}$ filter. The filter paper was oven dried at $100^{\circ} \mathrm{C}$ for $24 \mathrm{~h}$ prior to and after filtration and the difference in mass taken as the mass of material eroded in the 24 hour period. This erosion rate was evaluated in terms of $\mathrm{g} / \mathrm{y}$ of buffer material eroded.

Throughout the course of the experiment, timelapse image analysis was undertaken by way of a DSLR camera mounted over the cell, controlled by video velocity image capture software. The images obtained were then used in conjunction with ImageJ software to quantify regions of interest including the total area of extruded material and the total area of the accessory-mineral ring. Threshold parameters were set with respect to saturation and brightness in order to isolate the respective regions and the same parameters applied to images at set intervals in the time series. The three data sets of swelling pressure, erosion rate and accessorymineral ring area were then evaluated with respect to time and each other.

\section{Results}

The flow rate of deionized water through the cell was $\sim 0.95 \mathrm{ml} / \mathrm{min}$ for a period of 130 days, with the 
exception of three periods: (1) two periods in which the flow rate was reduced to approximately half of this value (when it was not possible to attend to the experiment to change the effluent bottle); (2) one three-day period in which a peristaltic pump pipe was changed, resulting in an increase in flow rate (see Fig. 2a). Figure $2 b$ shows that the swelling pressure generated by the bentonite increased rapidly, corresponding with initial water uptake and saturation, to a value of $515 \mathrm{kPa}$ over the course of 1 week. The swelling pressure then decreased over the course of an approximate 90 day period to a value of $350 \mathrm{kPa}$ before stabilizing around this value for the remaining 40 days. Of note in Fig. $2 b$ is that after the initial swelling-pressure rise, whilst the general trend is decreasing, the swelling pressure exhibits regular periodic fluctuations.

During the 130 days of the test, $\sim 1.11 \mathrm{~g}$ of the $4.67 \mathrm{~g}$ of dry mass of bentonite initially emplaced was eroded, i.e. $24 \%$ of the initial sample mass. Figure $2 c$ shows that the erosion rate (when scaled) increased to $8.8 \mathrm{~g}$ per year during the first 23 days of the experiment and then decreased gradually over time. Most apparent however is a clear and regular oscillation in the erosion rate that has a period of $\sim 10$ days.

Figure 3 highlights the evolution of bentonite extrusion (from the sample emplaced beneath the brass plug) into the fracture after 10, 50, 90 and 130 days. As bentonite extrudes into the fracture the accessory minerals, which are predominantly darker in colour, are transported along with the lighter-coloured montmorillonite particles. This process of swelling and extrusion results in decreasing density of the bentonite with radial distance from the central plug. At the edge of the extrusion zone, where the density of the bentonite is very low and is in contact with the flowing deionized water, the montmorillonite particles are susceptible to erosion through the formation of colloids. These colloids are eroded by the advective fracture flow, leaving the larger diameter accessory minerals behind. As more bentonite extrudes into the fracture from the central compartment, more accessory minerals are transported and thus the thickness of the accessory-mineral ring increases.

The area covered by the accessory minerals was evaluated every $24 \mathrm{~h}$ by quantitative image analysis; this method of analysis has been highlighted in Fig. $3 d$. What appears to be a bentonite density gradient is clearly visible in Fig. 3 by the radial colour change across the extruded material. Figure $2 d$ shows that significant extrusion occurs up to 40 days, with an initial rapid extrusion period of 6 days corresponding to the initial wetting phase. After this 40-day period, the overall zone of bentonite extrusion increases more gradually. During this 40-day extrusion phase, the accessorymineral ring exhibits a period of rapid growth, which commences at approximately 14 days as illustrated in Fig. 2d. This continues for 26 days before also increasing more gradually. This period of gradual growth of the mineral ring occurs in a stepwise fashion, with periods of relative stability and periods of increased growth rate. The accessorymineral ring also appears to take on a more distinct 'cog' type shape over time (Fig. 3).

The initial increase in erosion rate, up to $8.8 \mathrm{~g} / \mathrm{y}$ over a 23 day period (Fig. 2c), is due to the simultaneous increase in the surface area of the bentonite in contact with the flowing water, as the bentonite extrudes radially into the cell. The subsequent decrease in erosion rate corresponds to the growth and establishment of the accessorymineral ring, as depicted in Fig. 2e. This supports the theory put forward by Richards and Neretnieks (2010) that the accessory-mineral ring can indeed function as a granular, porous filter medium, allowing fewer and fewer montmorillonite particles through as it grows. It is also apparent that during each period of increased erosion, the accessorymineral ring continues to grow (Fig. $2 c, d$ ). As the ring is supplemented by incoming accessory minerals, the thickness of the ring increases and the porosity of the ring reduces as smaller accessory minerals are strained within the accessory-mineral ring matrix.

When the swelling pressure data are analysed, alongside both the oscillations in erosion rate and the increasing area of the mineral ring, a cyclic twostage mechanism governing the erosion process becomes apparent. Figure 4 shows erosion, swelling pressure and mineral-ring area data for two cycles that cover a time period from 48 to 86 days.

Stage 1: In Fig. 4a,i, 49-61 days, the erosion rate is relatively stable at $2-3 \mathrm{~g} / \mathrm{y}$. During this period, the swelling pressure rises steeply by $\sim 60 \mathrm{kPa}$ (Fig. $4 b$, i). This pressure rise occurs because the rate of water uptake in the swelling bentonite plug exceeds the rate of mass loss due to erosion. The accessory-mineral ring area during this stage increases at a slow rate (Fig. $4 c$, i).

Stage 2: Stage 2 is initiated by a breach in the accessory-mineral ring. This breach occurs when the rising swelling pressure exceeds the strength of the force chains developed in the mineral ring against the variable aperture wall. The breach causes (1) an increase in the rate of montmorillonite 
CHRISTOPHER REID ETAL.

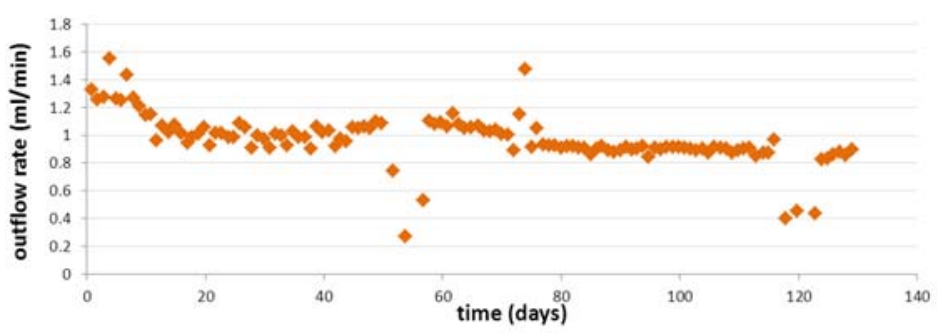

a)

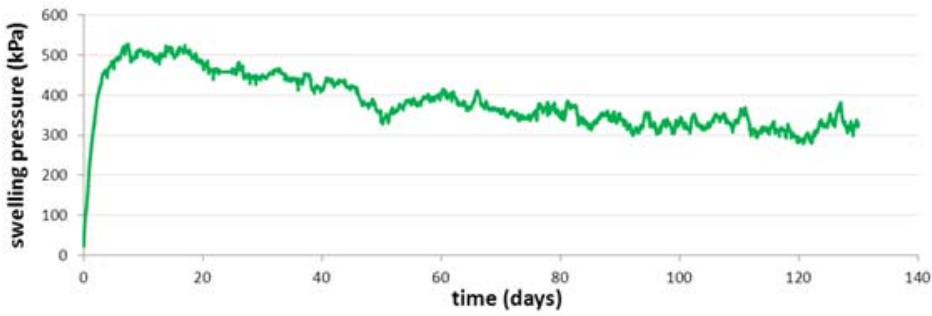

b)

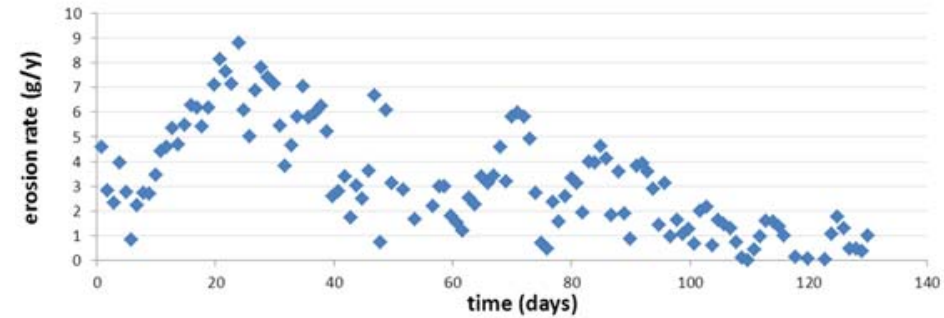

c)

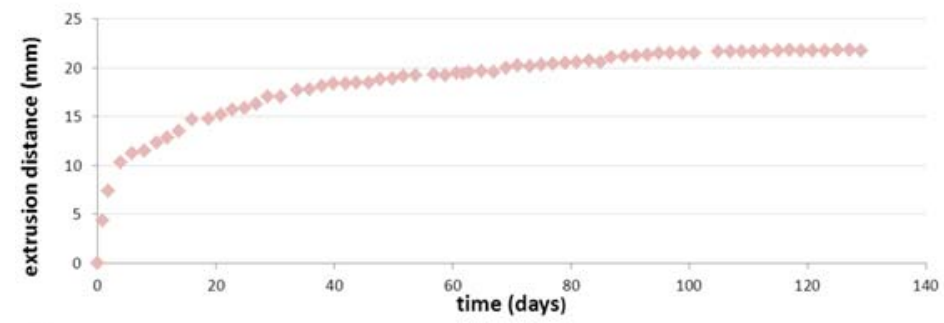

d)

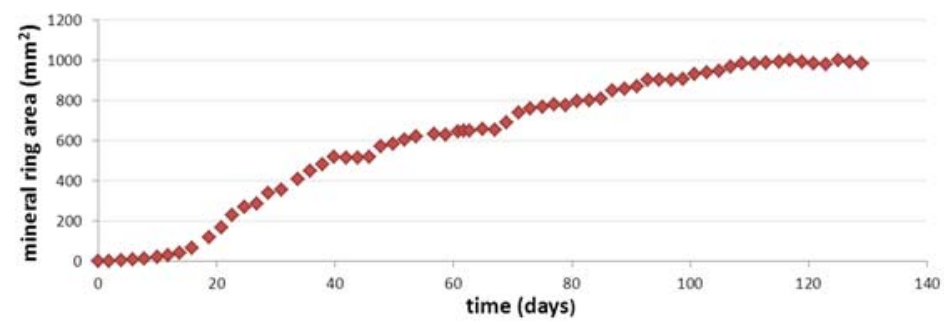

e)

FIG. 2. (a) Effluent outflow rate $v s$. time; (b) swelling pressure $v s$. time; $(c)$ erosion rate $v s$. time; $(d)$ radial extrusion distance $v s$. time; and $(e)$ accesory mineral-ring area $v s$. time. 


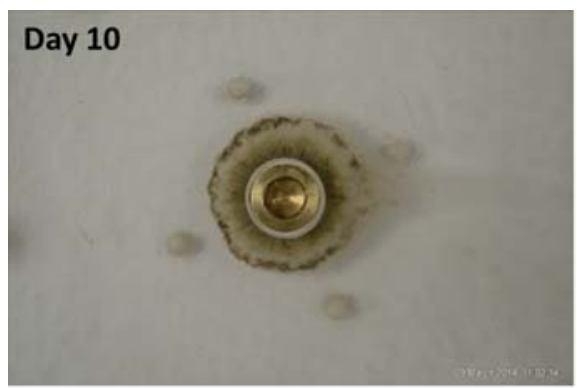

a)

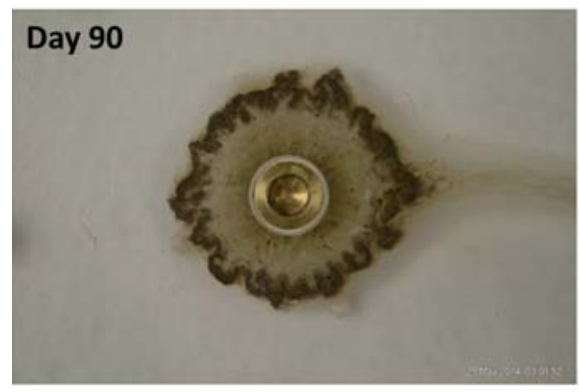

c)

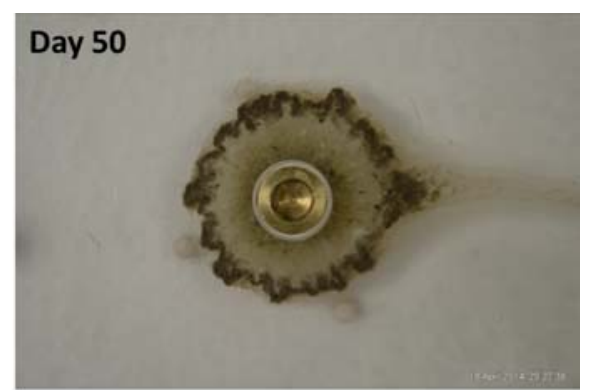

b)

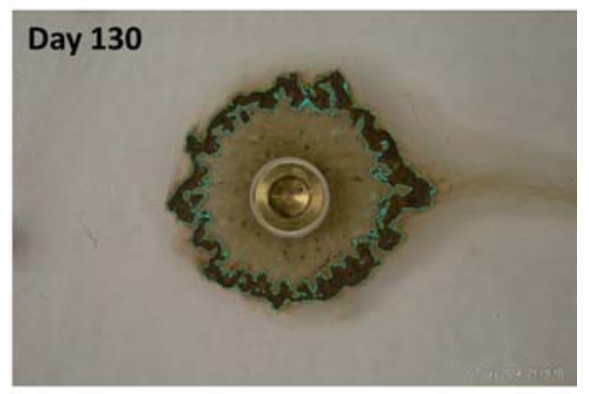

d)

Fig. 3. (a) Extrusion into fracture after day 10; (b) extrusion into fracture after day 50; (c) extrusion into fracture after day 90; and $(d)$ extrusion into fracture after day 130 with the evaluated accessory-mineral ring area highlighted.

erosion (Fig. 4a,ii) as the advective flow of deionized water comes into contact with bentonite that was previously protected by the accessorymineral ring and (2) a pressure drop at the edge of the extruded area. As a result of this pressure drop, transportation of bentonite from the central compartment is enhanced. During Stage 2, the swelling pressure decreases (Fig. $4 b$,ii) as the rate of mass loss from the central compartment exceeds the rate of water uptake. After the initial breach, the accessory-mineral ring area grew rapidly as the rapidly eroding montmorillonite leaves behind its accessory minerals.

Once the mineral ring has regained its integrity and hence its filtration capacity, the whole cycle begins again. So, erosion rate decreases (Fig. 4a,iii), swelling pressure increases (Fig. $4 b$,iii) and the rate of increase in the area of the mineral ring decreases (Fig. $4 c$,iii). The ring then breaches once again and the process of increased erosion corresponding with decreasing swelling pressure repeats (Fig. $4 a$,iv, $b$ iv, $c$ iv). The delay in the rapid growth rate of the mineral-ring area during stage 2 of each cycle is because it takes time for new accessory minerals to be transported to the edge of the extruded bentonite.
The cyclic, two-stage erosion mechanism was evident from day 48 to 100 . After 100 days the (gradually thickening) accessory-mineral ring was sufficiently strong that the swelling pressure was no longer sufficient to breach the ring.

\section{Discussion}

The maximum recorded swelling pressure of $0.515 \mathrm{MPa}$ is much lower than the $2-10 \mathrm{MPa}$ buffer swelling pressure that is expected in a repository scenario (Juvankoski et al., 2012). This can be attributed to the presence of voids in the compartment, due to the internal threading on the upper half of the compartment to accommodate the brass plug and the fact that the pellet has to be marginally smaller than the compartment to allow for installation. The pellet is therefore initially free to swell into these voids, increasing the volume of voids ( volume $_{\text {voids }}$ ) in the bentonite. Furthermore, a decrease in the volume of solids (volume solids $_{\text {) }}$ in the compartment results from extrusion of material into the fracture. Overall, this leads to an increase in the void ratio, $e$, where $e=$ volume $_{\text {voids }}$ /volume solids $_{\text {. }}$ Based on data on the relationship between swelling 


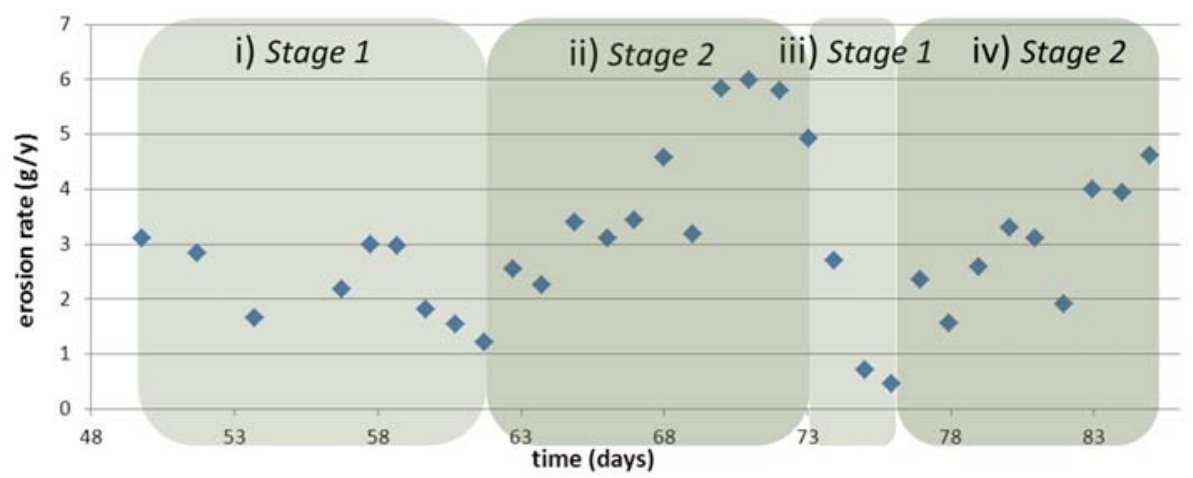

a)

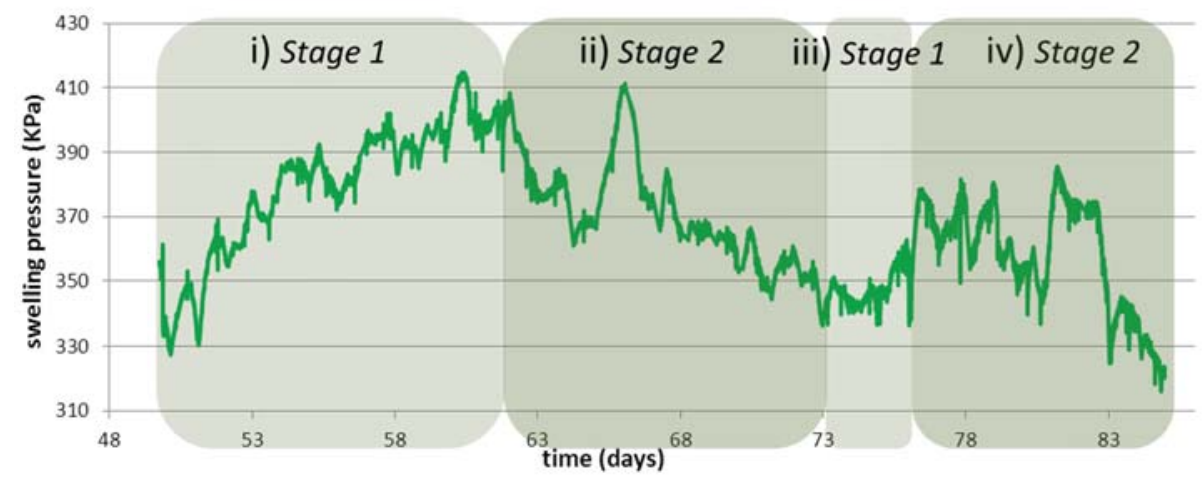

b)

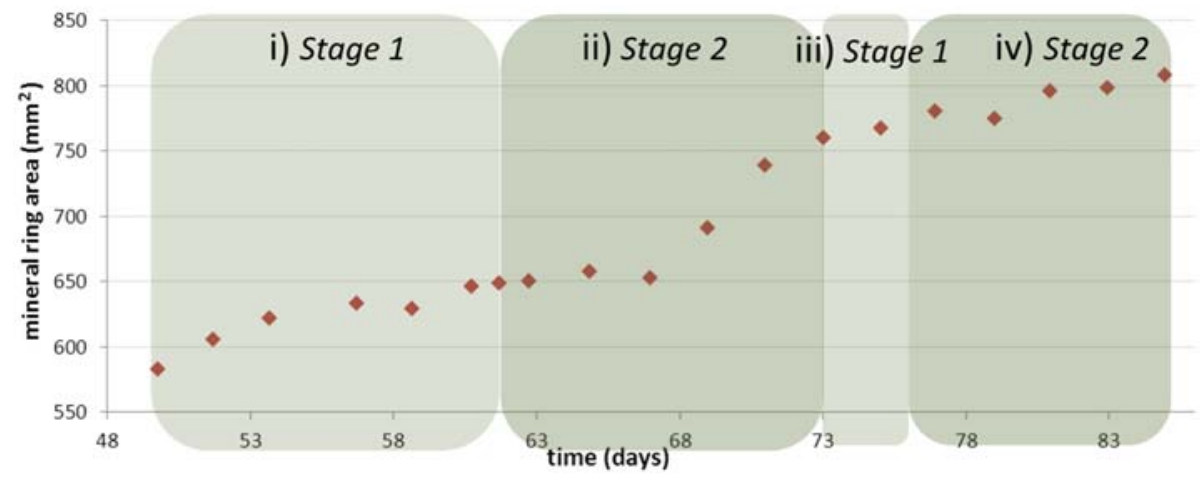

c)

FIG. 4. The two-stage erosion cycle: $(a)$ erosion rate $v s$. time; $(b)$ swelling pressure $v s$. time; $(c)$ accessory-mineral ring area $v s$. time

pressure and void ratio, $e$, for MX-80 bentonite (Cui and Tang, 2013), an increase in void ratio due to these combined effects may decrease the swelling pressure by an order of magnitude. The overall decrease in swelling pressure observed during the experiment is attributable to the fact that $\sim 24 \%$ of the specimen was eroded.

The model of Neretnieks et al. (2009) is applicable in the case of the erosion of purified Na-montmorillonite. Equation 1, does not take into 
account the presence of accessory minerals and thus isn't directly comparable to the experiment presented here. It is, however, currently used by SKB to predict buffer erosion in their safety case and given the upper limit on montmorillonite content of the buffer of $90 \%$ (SKB, 2010), the buffer will certainly contain some accessory minerals. Applying equation 1 to the experiment presented here gives a predicted erosion rate of $44 \mathrm{~g} / \mathrm{y}$. This compares to a maximum observed experimental erosion rate of $8.8 \mathrm{~g} / \mathrm{y}$ and a final observed rate of $<2 \mathrm{~g} / \mathrm{y}$. These observed erosion rates are of the same order of magnitude as those recorded by Schatz et al. (2013) who, in addition to work undertaken on purified montmorillonite samples, also conducted two tests on MX-80 in a flat-plate erosion cell and recorded rates of 1.54 and $2.77 \mathrm{~g} / \mathrm{y}$ at a flow rate of $0.1 \mathrm{ml} / \mathrm{min}$. Hence, experimentallyobserved erosion rates for MX80 are consistently one order of magnitude less than those calculated by the current models that are based on purified $\mathrm{Na}-$ montmorillonite, highlighting the degree of conservatism currently employed in SKB's safety case with regard to buffer erosion.

It was also noted by Schatz et al. (2013) that an increase in flow rate (and thus fluid velocity) may result in an increase in erosion rate, as far as purified montmorillonite systems are concerned. This is incorporated in SKB's model of buffer erosion (equation 1). However, in our study, an increase in flow rate from 0.9 to $1.5 \mathrm{ml} / \mathrm{min}$ over the 3 day period from 72 to 75 days, as illustrated in Fig. $2 a$, actually corresponded to a (Stage 1) period of rapidly reducing erosion rate (Fig. 2c), suggesting that flow rate is not a key factor governing the erosion rate when accessory minerals are present.

As the accessory-mineral ring increases in thickness it appears to adopt a 'cog' like structure (Fig. 3) which, according to image analysis, appears more susceptible to breaching at its concave regions. One possible explanation for this structure is that the rate of increase of the extrusion distance of bentonite into the fracture is too slow to accommodate the rate of growth of the accessorymineral ring; hence the ring is forced to concertina at the circumference of the extruded material. In a repository scenario, it is the case that saline groundwater conditions may prevail for many thousands of years. During this time, buffer extrusion into any fractures would occur before erosion was initiated by a period of glaciation. Therefore, the accessory-mineral ring would not begin to accumulate until after the bentonite had extruded. However, physical straining of the accessory minerals due to rough fracture apertures is still likely to occur. Once erosion begins, an accessory-mineral ring will gradually accumulate and the buffer could be designed to accommodate a sacrificial mass of montmorillonite that is allowed to erode before the accessory-mineral ring becomes sufficiently thick that it acts as a filter.

The initial magnitude of erosion upon intrusion of dilute groundwater would probably be dependent on the chemical composition of the groundwater, groundwater velocity and the extent of extrusion, i.e. the surface area of buffer in contact with groundwater at the buffer/ groundwater interface. Naturally, the interface between the groundwater and buffer would occur at a greater distance relative to the deposition hole, than in these experiments. Furthermore, the swelling pressure generated by the bentonite in the deposition hole would be far greater than that described in this manuscript. However, the gradient of bentonite density and swelling pressure across the extruded material from deposition hole to the buffer/groundwater interface within the fracture would still be present in a full-scale scenario. Considering the buffer/groundwater interface presented herein to simulate the interface in the full scale (rather than the entire system), there is no reason to suggest that the response in a fully saturated, repository scenario, of rising swelling pressure causing perturbations in the accessorymineral ring and cyclical erosion, would be any different. It is, however, likely that the timescales over which this cyclical erosion behaviour may occur would be far greater.

Natural processes that increase fracture apertures may work to the detriment of a mineral ring filter over the course of repository evolution. These include shearing along rock fractures and unloading of the overburden, such as in the case of a retreating glacier. The corresponding changes to the fracture could disturb, and possibly breach, the accessorymineral ring thus it would take time for the accessory-mineral ring to reform and once more gain sufficient integrity to inhibit buffer erosion.

\section{Conclusions}

This study has demonstrated that the accumulation of a ring of accessory minerals does indeed provide a mitigating effect against erosion of MX-80 bentonite extruded into fractures. The erosion process, in which an accessory-mineral ring forms, is governed by a two-stage cyclic erosion 


\section{CHRISTOPHER REID ETAL.}

mechanism: increasing swelling pressure causes a breach in the accessory-mineral ring, triggering a subsequent erosive period. During this period, the mineral ring is supplemented and the breach is healed. The cycle repeats until the ring is sufficiently strong that the ring remains intact. This observed process of mineral-ring formation results in erosion rates one order of magnitude less than those currently used in long-term safety-case calculations.

\section{References}

Apted, M.J., Arthur, R., Bennett, D., Savage, D., Sällfors, G. and Wennerström, H. (2010) Buffer erosion - An overview of concepts and potential safety consequences. SSM report 2010-31.

Cui, Y. and Tang, A.M. (2013) On the chemo-thermohydro-mechanical behaviour of geological and engineered barriers. Journal of Rock Mechanics and Geotechnical Engineering, 5, 169-178.

Juvankoski, M., Ikonen, K., and Jalonen, T. (2012) Buffer production line 2012: Design, production and initial state of the buffer. Posiva report 2012-17.

Kiviranta, L. and Kumpulainen, S. (2011) Quality control and characterisation of bentonite materials. Posiva work report 2011-84.
Neretnieks, I., Moreno, L. and Liu, L. (2009) Mechanisms and models for bentonite erosion. SKB Technical Report TR-09-35, Swedish Nuclear Fuel and Waste Management Co., Stockholm.

Richards. T. (2010) Particle Clogging in Porous MediaFiltration of a Smectite Solution. SKB Technical Report TR-10-22, Swedish Nuclear Fuel and Waste Management Co., Stockholm.

Richards, T. and Neretnieks, I. (2010) Filtering of clay colloids in bentonite detritus material. Chemical Engineering Technology, 33, 1303-1310.

Schatz, T., Kanerva, N., Martikainen, J., and Sane, P. (2013) Buffer erosion in dilute groundwater. Posiva report 2012-44.

SKB (2010) Design, production and initial state of the buffer. SKB Technical Report TR-10-15, Swedish Nuclear Fuel and Waste Management Co., Stockholm.

SKB (2011) Long-term safety for the final repository for spent nuclear fuel at Forsmark. Main report of the SRSite project. Updated 2012-12. Technical Report TR11-01.

Vilks, P. and Miller, N.H. (2010) Laboratory bentonite erosion experiments in a synthetic and a natural fracture. NWMO Technical Report TR-2010-16.

Witherspoon, P.A., Wang, J.S.Y., Iwail, K. and Gale, J.E. (1979) Validity of cubic law for fluid flow in a deformable rock fracture. Water Resources Research. 